\title{
El episodio del henequén en Yucatán*
}

Howard F. Cline

Debido a los torrentes de riqueza que se han derramado sobre la peninsula, se ha llamado popularmente al henequén "oro verde" de Yucatán. Durante la primera mitad del siglo XIX, la industria que se desarrolló en Yucatán en torno al cultivo, procesamiento y venta de fibras de los agaves llamados genéricamente "plantas de henequén" logró lo que la mayoría de la gente esperaba de la producción de azúcar. En un príncipio el henequén proporcionó una fuente adicional de riqueza y empleo, y luego reemplazó las actividades económicas coloniales.

La industria del henequén comenzó a ser una ocupación comercial redituable después de la Independencia, pero por razones que se mencionarán más adelante, al iniciarse la guerra de Castas no había alcanzado un punto de desarrollo tan alto como el cultivo de caña de azúcar. No obstante, de 1830 a 1860 se asentaron los cimientos básicos para su veloz desarrollo posterior y dejó de ser un sueño de los literatos de la Colonia para hacerse realidad y desempeñar una función significativa en el panorama yucateco de 1830 a 1847. Después de la guerra de Castas, el henequén cumplió la función de amortiguar los impactos económicos.

A diferencia de la caña de azúcar, que era una planta importada, los agaves semejantes a cactos que reciben el nombre de henequén son de origen autóctono. Los mayas ya conocían y utilizaban especialmente para cordeleria las largas fibras extraidas de sus hojas desde antes de la Conquista, pero en contraste con algunos otros grupos de Mesoamérica, las prendas de vestir hechas de henequén apenas se mencionan en los registros de los mayas yucatecos. Al parecer, los colonizadores españoles no realizaron ningún intento para organizar la explotación comercial del henequén hasta que los Borbones llegaron al trono en 1700 . Hacia la segunda mitad del siglo XVIII, algunos escritores atrajeron la atención sobre las posibilidades que podía ofrecer su cultivo.

El informe de Valera y de De Corres en 1766 era optimista respecto a las enormes ganancias imperiales que se podian obtener tanto del henequén y de otras fibras yucatecas como de otros recursos locales que reforzarían el sistema económico del imperio español. Hicieron una relación de los diversos usos de las fibras que servian para la fabricación de mosquiteros y costales, pero principalmente para el cordaje de los barcos, que era superior al holandés. En 1783 un oficial de marina yucateco tomó en cuenta

* Publicado en Interamerican Economic Affairs, vol. 2, núm. 2,.1948, p. 30-51. Trad. Federico Martínez Delamain y José Ortiz Monasterio. 
su informe, pues previó que costales, maromas y sogas manufacturados con henequén beneficiarian a la marina española y enriquecerian a Yucatán. Con esas ganancias, la península sería capaz de erigir y mantener "sus ilustradas academias, sus brillantes universidades, sus hermosas instituciones, que hoy constituyen el aspecto más admirable del progreso de las artes y ciencias de Europa".

Una opinión similar sobre la utilidad y futuro del henequén se manifestó en los momentos de agonia de la época colonial (principios del siglo XIX). En 1814, un economista político abogaba por una acción conjunta para fomentar su expansión, mejorar los métodos de cultivo y controlar los precios; pidió que le asignara un grupo particular la responsabilidad de esos asuntos y la de ofrecer gratificaciones por la expansión y mejora del cultivo. Señaló que una industria como la que él concebía emplearía provechosamente a la población nativa llevando asi a toda la estructura social los beneficios de la prosperidad; afirmó categóricamente que comparada con el henequén "no existe mina de oro o plata tan útil, porque sus beneficios alcanzan a innumerables trabajadores, que pueden integrarse como mano de obra".

A pesar de que hacia finales de la época colonial se expresaron firmes esperanzas acerca del futuro del henequén como mercancia, y aunque la Corona española no tomó ninguna medida para impedir su cultivo (como lo hizo con la caña de azúcar), sólo después de que Yucatán se separó de España se estableció una actividad comercial verdaderamente importante. En 1783 no había bodegas de empaque ni otras instalaciones permanentes para procesar las fibras, que se extraian mediante métodos manuales tradicionales y primitivos; los instrumentos que se empleaban eran los talladores de mano, conocidos como toncos o pacché.

Aparentemente, en 1828 se dio el primer paso para dotar a la industria de una base más estable que la que había tenido hasta entonces. En abril el gobierno del estado mostró oficialmente su entusiasmo en cuanto al potencial del henequén. La legislatura ordenó que cada ciudadano cultivara por lo menos diez plantas de henequén al año en su huerto particular y que las autoridades municipales y las repuiblicas de indigenas hicieran cubrir de agaves todos los lotes baldios de sus comunidades, así como las propiedades públicas de sus alrededores.

A pesar del hecho de que este decreto no creó una industria, parece claro que el deseo de fomentar el cultivo del henequén llegó al punto de elaborar planes concretos para su explotación comercial; el reino de la palabra cedió su lugar al de la acción. Desde 1828 hasta alrededor de 1854 (un año después de haberse terminado nominalmente la guerra de Castas), se produjo un importante periodo de exploración técnica. Las siguientes dos décadas se construyeron sobre esas bases, mejorando métodos y técnicas de cultivo, producción y comercialización. Así cuando se difundió el uso de la segadora McCormick que exigía cantidades casi ilimitadas de cordel hecho de henequén, Yucatán estaba preparado y tenía la capacidad necesaria para producirlo sobre una base monopolizadora. La historia del henequén después de alrededor de

En español en el original. (N. del T.) 
1880 es bastante conocida y constituye más apropiadamente parte de la historia económica general de México. La evolución de la industria local hasta 1860 no ha sido tan difundida.

Como puede deducirse fácilmente de lo que hasta aquí se ha dicho, la industria del henequén que se desarrolló después del primer tercio del siglo XIX se basaba en el cultivo comercial de agaves, el procesamiento de sus hojas para extraer fibras naturales y la venta de las fibras en estado bruto o manufacturado. Algunos elementos naturales condicionaron su desarrollo debido a la peculiar naturaleza de los agaves. Si bien incluso hasta la fecha los botánicos no han estudiado ni descrito a fondo la taxonomía de los agaves yucatecos, para los propósitos de este trabajo sus caracteristicas se conocen suficientemente.

Comercialmente se han cultivado múltiples variedades de esta amarilidea; la más común es el henéquen blanco o sacqui (agaves fourcrol'des, Lem). En 1845 un escritor se refirió a los agaves como un producto "que constituye nuestro tesoro agrícola e industrial verdaderamente grande y particular". Una variedad verde comúnmente llamada yarqui o babqui se cultivó particularmente en la zona oriental de Yucatán para fabricar hamacas, mientras que algunos tipos silvestres tenian otros usos particulares, casi siempre locales.

Dos particularidades de estos agaves contribuyeron a dar forma a la industria que se basó en ellos. Una es que la región semiárida de caliza que rodea a Mérida hacia el este aproximadamente hasta Chichén, hacia el sur hasta Ticul y Yaxcabá, hacia el oeste y norte hasta las márgenes de los pantanos costeros, proporcionaba las condiciones óptimas de humedad y suelo para el henequén, que no eran particularmente favorables para otros cultivos. El henequén no competia con el maiz por tierra y agua. La segunda característica importante es que entre la siembra original y la primera cosecha de hojas que producirá cantidades significativas de fibra transcurre un considerable lapso de tiempo. Este periodo puede variar entre cinco y ocho años, dependiendo de la variedad de la planta y del momento en que el empresario considere redituable el producto del primer corte. La planta tiene un promedio de vida de veinte años; por lo menos los primeros cinco, mientras madura, son improductivos; los siguientes diez años son los de más alto rendimiento y éste decae en los últimos años.

Partiendo de cero, un agricultor de henequén se ve forzado a invertir en mano de obra sumas considerables durante cinco años sin recibir utilidades, además del costo original de la tierra y del equipo. Al terminar el vigésimo año, toda la empresa tiene que ser virtualmente abandonada y reiniciada en algún otro lugar. Aunque en varios momentos de su existencia la industria del henequén se diseminó sobre toda la mitad norte de la península -al grado de que por un tiempo casi suprimió al maíz-generalmente se ha concentrado en el cuadrante noroeste, en una zona ahora bien reconocida como "la zona henequenera", comparable en gran medida con lo que en estas páginas llamamos Old Colonial. ${ }^{2}$

\footnotetext{
- En sus numerosos trabajos sobre el Yucatán del siglo XIX. el autor utiliza una denominación propia para diferenciar cuatro regiones geográfico-sociales en las que divide a la peninsula de Yucatán: Old Colonial. West Coast. East Colonial y
} 
Cuando alcanzó su completo desarrollo, las necesidades y características de la industria henequenera fueron muy parecidas a las que tuvo en sus inicios. Se trataba de un producto cultivado a gran escala en las haciendas, que requería la inversión de un capital inicial considerable, muy por encima de las posibilidades de los agricultores mayas nativos. En 1916 los agricultores de henequén yucatecos acordaron ante un comité del senado norteamericano, que se necesitaba un desembolso inicial mínimo de más de 130000 dólares para instalar una hacienda mediana y para mantenerla hasta antes de obtener cualquier producto comercializable; aproximadamente la mitad de esa suma se destinaba a equipo de producción, sin contar la tierra.

La fibra del henequén ha sido casi exclusivamente un producto de exportación, ligado a la estructura y al mercado financiero internacional. La transportación desde la península a los mercados externos no ha estado en manos de yucatecos, pero casi todos los elementos internos relativos a la producción -incluyendo el transporte al puerto de desembarco- permanecieron bajo control de yucatecos. Cuando en 1856 un francés aspiraba a obtener un monopolio oficial, con el "privilegio exclusivo, por un periodo de treinta años, de cultivar, procesar y exportar plantas textiles e hilaturas de la región", los yucatecos reaccionaron con su fervor característico (reminiscente de los comerciantes de sal del siglo XVIII). La petición fue rechazada por oposición unánime, a pesar del respaldo que le dio José Limantour; el control local de la producción henequenera es aún un rasgo digno de mención.

La producción de la fibra para su exportación incluye el cultivo de las plantas y luego la selección de las hojas maduras para extraer los filamentos. La primera fase no es tan susceptible de desarrollo tecnológico como la segunda. Desde un principio ambas se realizaban en una sola hacienda, unidad productiva básica. Una vez que se ha limpiado y plantado el campo por primera vez, el principal costo de mano de obra es el de mantenerlo deshierbado y limpio, cortar las hojas maduras de la planta en crecimiento y apilarlas para llevarlas al lugar de desfibrado. Se necesita una fuerza de trabajo estable durante todo el año. En épocas anteriores el número de trabajadores necesarios para limpiar los manojos de hojas o pencas, era mucho mayor que el requerido para el cultivo. El complejo establecimiento henequenero de los tiempos modernos en muchos aspectos tiende a parecerse más a una fábrica rural que a la holgada finca de subsistencia que generalmente implica el término "hacienda".

El prototipo de la finca henequenera de los últimos tiempos apareció en Yucatán en septiembre de 1830. Un grupo de yucatecos se asoció y formó una corporación, quizá la primera institu-

Borderlands. El término Old Colonial designa el área localizada en la porción noroccidental de la península, que abarca los distritos de Mérida e Izamal, y comprende las poblaciones de Maxcanú. Ticul, Sotuta, Izamal y Motul. En el centro de esta zona se encuentra la ciudad de Mérida, alrededor de la cual se establecieron durante la Colonia numerosas haciendas ganaderas que exportaban carne y ganado, principalmente a Cuba, y que desde las primeras décadas del siglo xix se dedicaron al cultivo del henequén. La población de esta región estaba formada principalmente por blancos. superando ligeramente o al menos igualando a la población maya. (N. del T.) 
ción moderna de este tipo en Yucatán, cuyo objetivo era promover, perfeccionar e incrementar el cultivo del henequén, así como coadyuvar a su manufactura y utilización. Treinta acciones proporcionaron un capital total de 7500 pesos para estos fines. Uno de los primeros pasos que tomó la corporación fue comprar la hacienda Chaczikin, donde se plantó un campo de henequén comercial. El costo de la hacienda fue de 838.37 pesos, y la parcela, de alguna manera experimental, era de 800 mecates, aproximadamente 80 acres. $^{3}$

Probablemente el camino más usual era transformar gradualmente una propiedad productora de maíz y ganado añadiendo un nuevo cultivo, más que la adquisición directa de una hacienda con el único propósito de cultivar henequén. Gerónimo Castillo describió una típica hacienda de la zona Old Colonial e incluyó como una de sus características en la década de 1840 "un inmenso henequenal cuyos límites se perdian en el horizonte y visto con ojos entrecerrados bajo la sombra, al nivel de las hojas más altas, asemejaba una inmensa bahía poblada de navios cuyos mástiles eran los tallos erguidos y ondulantes de las plantas viejas y abandonadas".

La hacienda Yaxcopil ilustra el proceso de transformación; llegó a ser una de las mayores productoras de henequén. El doctor Ignacio Vado la adquirió en una subasta en 1846; nunca antes se había cultivado ahí el henequén. Cuando en 1864 el lugar volvió a cambiar de dueño, la hacienda tenía algo más de 240 acres de henequén, valuados en 4868.75 pesos, y producía fibra desde 1852 (lo cual implica que Vado la plantó poco después de adquirirla). Eventualmente, después de 1864 , se sembraron más de 5000 acres de henequén.

Los cálculos para 1846 se basaron en la práctica de plantar 81 agaves por cada mecate de tierra, y bajo la premisa de que se podian cortar 75 hojas al año de cada planta madura. Una arroba ${ }^{4}$ de fibra comercializable requería alrededor de 475 de esas hojas. Cada mecate produciria a este ritmo 6075 hojas, equivalentes a 13 arrobas de fibra después de ser procesadas. En 1861 sólo se plantaron 64 tallos por mecate, esperando que cada uno produjera sólo 25 manojos o sea 1600 por mecate. Se pensaba que una arroba de fibra útil requeriria de 500 hojas. Así, para esa fecha, se pensaba que sólo se podían producir un poco más de tres arrobas por mecate. El porqué de tan grande discrepancia entre los cálculos iniciales y los posteriores, parece inexplicable; en cada caso la gente de la época estaba de acuerdo en que los cálculos para 1846 y para 1861 eran básicamente correctos. No obstante, concordaban en que tenian que ser procesadas casi 500 hojas para producir una libra de fibra.

En cierto modo el pago por el cultivo permaneció estático. En la primera plantación de 1830 , los dueños colectivos de Chaczikin pagaron a un real el mecate por cada escarda, un proceso requerido dos veces al año; la misma tasa estaba en vigor en 1861. Para 1916, el pago se había cuadruplicado. En 1830, el corte de las hojas maduras costaba entre 1.00 y 1.25 pesos el millar; no se

\footnotetext{
${ }^{3}$ Un acre $=0.445$ ha: un mecate $=404.5 \mathrm{~m}^{2}$. (N. del T.)

+ Una arroba $=11.325$ k. (N. del T.)
} 
dieron cifras comparables para 1861 , pero parece ser que para 1846 los cortadores habían sido elevados al rango de asalariados permanentes, con un sueldo de cuatro pesos más cierta cantidad de maiz al mes. Entonces se necesitaban dos hombres para cortar el producto de 142 mecates; para recibir salarios y maíz cercanos a los 100 pesos, cortaban más de 8.5 millones de hojas, que volvian insignificante el costo por millar. En 1916 el precio por el corte de mil hojas era de 2.00 pesos y representaba alrededor del $16 \%$ del costo de operación por mecate. Desde sus comienzos y hasta la fecha, los campos de henequén se han sembrado, limpiado y cortado manualmente sin que puedan lograrse muchas mejoras.

Sin embargo. la expansión del cultivo no estaba limitada por sus propios elementos siempre que se suministrara mano de obra suficiente. La tierra en que el henequén crecía mejor no producia otros cultivos de mayor valor y era relativamente extensa. La guerra de Castas ayudó a resolver el problema inicial de mano de obra; en muchos casos los mayas y mestizos que regresaron desde el este y el sur estaban más que dispuestos a buscar refugio y sustento en el norte y el oeste. En los años anteriores a la guerra de Castas, los principales obstáculos para aumentar la producción de fibra eran la carencia de mano de obra, de capital y las dificultades técnicas para procesar las hojas en bruto y convertirlas en fibras comercializables. Cada libra ${ }^{5}$ de fibra requeria de 500 hojas una tonelada corta ${ }^{6}$ necesitaba el tallado y desfibrado de un millón, ardua e insuficiente tarea hecha a mano.

Casi simultáneamente al establecimiento del primer plantio comercial de henequén en 1830 , se renovaron los esfuerzos para mejorar los métodos de desfibrado, con el fin de sustituir los tradicionales toncos por la mecanización. Uno de los objetivos de la sociedad que adquirió Chaczikin era perfeccionar la maquinaria que permitiría el incremento casi ilimitado del cultivo del henequén. De hecho, la esperanza de obtener una maquinaria como ésta pudo haber sido la razón original para formar la corporación; un mes antes de su inauguración formal y legal, en septiembre de 1830, se le concedió al grupo que después se convirtió en accionista. un monopolio por diez años para el uso exclusivo de una máquina desfibradora inventada por un tal Freeman Graham, con quien se firmó un contrato. Poco o nada se volvió a saber de esa máquina, y los numerosos esfuerzos, de 1830 en adelante y hasta cerca de fin de siglo, para inventar y mejorar maquinaria de desfibrado son una posible evidencia de que el aparato de Graham no satisfizo todas las esperanzas cifradas en él.

Como muchas actividades que cobraron importancia después de la Independencia, el intenso trabajo posterior a 1830 tuvo su antecedente a finales de la época colonial. No parece haber continuidad entre los intentos de un clérigo para crear una máquina desfibradora en 1783 (usando la rueda de una carreta con cuchillas fijas) y los inventos posteriores. La primera patente yucateca se otorgó a un americano en 1833, Henry Perrine. Era entonces cónsul en Campeche y tan entusiasta como cualquier yucateco sobre el futuro del henequén. Gracias a sus esfuerzos, los agaves se

\footnotetext{
"Una libra $=0.4536 \mathrm{k}$. (N. del T.)

" Una tonelada corta $=907.2$ k. (N. del T.)
} 
introdujeron en Florida, pero no logró producir el henequén que esperaba. Su máquina de 1833 probó ser demasiado difícil de manejar en algunos aspectos, y muy delicada en otros para que la usaran trabajadores nativos.

En la primera fase de la investigación tecnológica, los extranjeros tomaron la delantera. El siguiente que intentó resolver las deficiencias cada vez más evidentes del aparato de Perrine fue un suizo alemán. Fernando Salisch en 1840. El Congreso le ofreció una gratificación de 2000 pesos si podia demostrar a la Junta de Fomento de Mérida que su nueva máquina cumpliria con lo que él afirmaba que podia hacer, pero así como la de Perrine tampoco ésta fue la solución: un mecanismo bastante sencillo como para ser operado por mano de obra nativa, que cortara y desfibrara las hojas de forma peculiar del agave. Aparentemente el ofrecimiento de la gratificación se mantuvo en pie y los siguientes aspirantes fueron un par de neoyorkinos, James $K$. Hitchcock (empresario) y E. S. Scripture (ingeniero). Siempre se recordará que ellos inventaron y trataron de vender un nuevo sistema para extraer el agua de los pozos yucatecos. A principios de noviembre de 1846 expusieron brevemente las ventajas de una máquina que desfibraría una hoja por minuto; un motor movido por tracción de mulas haría trabajar a una bateria de desfibradoras, y al mismo tiempo sacaría agua.

Los neoyorkinos no tardaron en exponer con entusiasmo las ventajas concretas de su invento. Sus cifras mostraban que empleando un motor que movia seis desfibradoras, un agricultor podía obtener un ingreso neto anual de cuatrocientos pesos de un campo de 142 mecates o 1400 pesos de uno de 500 mecates. Un yucateco señaló que la idea de usar maquinaria para desfibrar no era nueva y que varios habian fracasado en las pruebas y solicitó que se diera una demostración pública de la maquinaria Hitchcock. El aparato desfibró, pero tan imperfectamente que destruyó parte de la fibra; además, su operación y mantenimiento parecian imposibles, ya que el complicado mecanismo no podía ser operado o reemplazado por el trabajador yucateco promedio.

En la misma época, un extranjero, Luis Koch, mostró otro artefacto. Antes de que también fallara, le asignó un precio de 2000 pesos a cada aparato y pidió una gratificación al gobierno de 10000 pesos. Se suponía que cada máquina desfibraria suficientes hojas para producir 40 arrobas de fibra al día; como se mencionó antes, esto significaría alrededor de 20000 pencas. Aún antes de la guerra de Castas llegó todavia otro extranjero, esta vez de Boston. Un tal Thompson que, con un ingeniero, trajo una máquina "cuyas demostraciones no fueron afortunadas". Al iniciarse la segunda mitad del siglo, los yucatecos escribieron: "Confiamos en que las esperanzas de la región se realizarán, si no gracias al estímulo del gobierno, entonces por intereses privados..."

Después de esta caterva de extranjeros fracasados, los propios yucatecos asumieron y resolvieron sus problemas, iniciando una segunda fase. Esta comenzó hacia 1850 y duró hasta 1860 . De 1861 en adelante, los problemas fueron menos complicados y consistieron principalmente en mejorar los aparatos existentes, sustituyendo la fuerza animal por vapor, adaptando correas transportadoras y herramientas similares a mecanismos cuyos principios 
habian probado su eficacia en décadas anteriores. Esta fue la tercera fase.

Muchos yucatecos se abocaron a la invención, pero debido a su éxito y tenacidad, se atribuye el crédito de proveer a la península de la maquinaria desfibradora necesaria a Manuel Cecilio Villamor y José Esteban Solis. Más que colaboradores, eran rivales; sus máquinas compartían esencialmente la misma idea fundamental, lo que los condujo posteriormente a un pleito judicial.

Ya desde 1854. la menguante dictadura centralista de Santa Anna en México, declaró a Villamor el inventor de la máquina desfibradora y le emitió una patente. En Yucatán se formó una compañia local para explotar los derechos de la patente, pero la desconfianza entre los socios (además de otras razones) desmembró al grupo: la única máquina que tenian se desmanteló y se vendió pieza por pieza a varios particulares. No mucho después de esto, en 1857. José Esteban Solís obtuvo una patente del gobierno del estado por un invento en cierto modo similar que incluía su monopolio por diez años. Cuando la emperatriz Carlota visitó Yucatán en 1865. lo premió por su hazaña con una medalla "al mérito civil", y en 1863 la legislatura del estado decidió que por fin tenía el motivo para pagar la gratificación de 2000 pesos por una desfibradora eficaz, ya que se habia extendido ampliamente el uso de la de Solís en Yucatán.

En 1871 Villamor demandó a Solís por usurpación de patente y le exigió 10000 pesos por danos y perjuicios. La primera corte que atendió el caso, se pronunció a favor de Solís, pero en la apelaciôn se revirtió el veredicto y se ordenó a Solis que pagara 4000 pesos por daños. En protesta, y debido a su reconocimiento por los beneficios recibidos de la que entonces y siempre se ha conocido como la "máquina Solís", los comerciantes de Mérida espontáneamente reunieron esa suma en su nombre.

Al final de la década de 1850 , cuando menos tres variantes de los principios Solís-Villamor incorporados a máquinas en operación estaban dando buenos resultados. En pruebas comparativas, la máquina de Solis superó a las construidas por Villamor y $\mathrm{Mi}$ llet: pero en el mejor de los casos difícilmente podía procesar más de 262 manojos por hora. Las de finales de siglo procesaban 20000 . En. la siguiente década se introdujeron otras máquinas destacando la que inventó Eduardo Juanes y Patrulló en Nueva York.

Pero el mayor desarrollo que se alcanzó en el periodo posterior a Solís fue la utilización de máquinas a vapor para desfibrar el henequén. En 1861 Eusebio Escalante, de quien se hablará más adelante, importó el primer motor a vapor aplicable a las desfibradoras y lo instaló en Itzincab. Al mismo tiempo importó una prensa especial para henequén como pieza complementaria. El perfeccionamiento de las máquinas y la ampliación de la mecanización en las unidades de producción continuó rápidamente, en 1872, por ejemplo, los agricultores pudieron ofrecer una recom: pensa de 20000 dólares a quien pudiera aumentar la eficiencia de las desfibradoras usadas comúnmente. Los hijos de Villamor se distinguieron especialmente por los nuevos instrumentos que disenaron para incrementar el rendimiento, mientras que un contemporáneo suyo, Manuel Prieto, construyó una máquina que hacia 
honor a su nombre de "La Vencedora", al desfibrar 20000 manojos por hora.

De este modo, cuando empezó a haber una demanda mundial sin precedentes de henequén (al difundirse ampliamente el uso de la segadora de McCormick, después de 1888), los yucatecos ya habían desarrollado y adaptado la tecnologia adecuada para satisfacerla. Para 1876, se usaban por lo menos seiscientas desfibradoras, de las cuales cuatrocientas trabajaban a vapor, y su potencia la producian predominantemente motores ingleses. Apenas unos cuantos años antes. Weikof estimó que Yucatán contaba sólo con cerca de cien desfibradoras a vapor. Los cimientos para esa evolución posterior se sentaron fundamentalmente entre 1830 y 1860 ; los esfuerzos iniciados antes de la guerra de Castas produjeron sólo unos cuantos resultados tangibles, pero al menos definieron con mayor claridad los problemas y reunieron un cúmulo de datos empiricos, generalmente de carácter negativo.

La propagación del cultivo del henequén siguió el ritmo del avance tecnológico, modificado por algunos elementos limitantes. La disponibilidad de capital, la demanda externa y la estructura del mercado, así como los acontecimientos políticos influyeron en su expansión, pero parece importante la sorprendente relación entre los mecates cultivados de henequén y la capacidad de procesamiento de las máquinas. Hasta fines de siglo e incluso después, hubo un mercado constante para toda la fibra que pudiera producirse. El cuadro I resume una serie de cálculos, algunos sobre bases un tanto esquemáticas, del número de mecates de henequén cultivados en diferentes años. Es notable la diferencia entre 1845 y 1847, pero es más significativo aún el incremento posterior a la mecanización que se inició en 1861 .

Antes de la guerra de Castas los agricultores tuvieron dificultades para financiar sus operaciones, y no hay datos fácilmente asequibles que indiquen cómo se enfrentaron a estos serios problemas. Un poco antes de 1861 se estableció la estructura financiera básica del comercio moderno del henequén, cuando Eusebio Escalante fundó una empresa comercializadora y consiguió una línea de crédito como filial de Thebaud Brothers de Nueva York. Mediante créditos personales, los henequeneros recibieron sumas por adelantado al $9 \%$ de interés anual. Un poco después, apareció una segunda filial de Thebaud Brothers, la firma yucateca establecida por M. Dondé, y en 1881 Miguel Espinosa Rendón se convirtió en socio de Bruggier and Company, también de Nueva York, que facilitó igualmente créditos a la península. Hacia finales de siglo (1895) G. Amsinck, de nuevo una casa de Nueva York, apoyó una empresa similar encabezada por Olegario Molina.

No se cubrió la demanda de capital hasta cerca del fin de siglo, como evidencian las tasas de interés. Alrededor de 1845, lo común era por lo menos $5 \%$, después de la guerra de Castas subió al $6 \%$; el $9 \%$ cargado por Escalante se convirtió en $18 \%$ y aumentó a $24 \%$ alrededor de 1875 . Un yucateco escribió entonces con cierta razón, que "más que ningún otro, el cultivo del henequén ha sido victima de la usura". Un intento para fundar en 1876 un banco local para henequeneros no pasó de ser un simple proyecto.

A diferencia de otros productos yucatecos antes de la guerra de Castas, el henequén encontró una amplia y creciente demanda en 


\section{CUADRO 1}

Mecates estimados de henequén

años seleccionados $1845-1890$

\begin{tabular}{|c|c|c|}
\hline $\operatorname{tin} 0$ & $\begin{array}{l}\text { Mecates } \\
\text { (en miles) }\end{array}$ & Notas \\
\hline
\end{tabular}

\begin{tabular}{rrl}
1845 & 16 & $\begin{array}{l}\text { Cosecha plantada hacia 1838; } \\
\text { desfibrado a mano. } \\
\text { Máximo anterior a la guerra } \\
\text { de Castas. }\end{array}$ \\
1847 & 60 & $\begin{array}{l}\text { Desfibradoras mecánicas; se } \\
\text { inicia el crédito extranjero. }\end{array}$ \\
1865 & 400 & $\begin{array}{l}\text { Primeras desfibradoras a vapor; } \\
\text { intervención francesa. }\end{array}$ \\
1878 & 780 & $\begin{array}{l}\text { Recuperación de los precios; meca- } \\
\text { nización ampliamente difundida. } \\
\text { La segadora McCormick requiere }\end{array}$ \\
1879 & 1130 & $\begin{array}{l}\text { cordel de henequén para empacar. } \\
\text { Máxima explotación del área } \\
\text { henequenera; nuevas máquinas. }\end{array}$ \\
\hline
\end{tabular}

FUENTES: Cálculos para 1845 y 1847 con la información de Regil y Peón, "Estadistica", 312-313: para 1860-78 y 1890, Cámara Zavala, Industria henequencra. p. 34, 45, 50-51: 1879 calculado con la información de "Cuadro de agricultura No. 28". Busto, Esladistica. I, y Baqueiro, Réseña, Doc. Núm. 3. [Los datos bibliográficos están incompletos en el original. N. del T.]

los mercados de exportación. Se utilizó principalmente en Estados Unidos y Cuba. El primero empleaba las fibras para diversos usos maritimos -jarcia, maromas de remolque para canal y similaresmientras que el henequén que entraba a La Habana era en forma de bolsas y costales para carbón vegetal y para la incipiente industria del café. cuyos empresarios descubrieron que el cáñamo de Manila tendía a pudrir los granos. Algunas cuantas hamacas y otros articulos manufacturados también tenían demanda entre los marinos. Estos productos del henequén más o menos tradicionales fueron las principales formas que éste tomó hasta alrededor de 1880. cuando se descubrió que no se pudria fácilmente lo cual lo convirtió en excelente cordaje para barcos, además de que la naturaleza de la fibra repelía a los insectos, la hacia idónea para entorchar. Por otra parte, el alambre utilizado hasta entonces para engavillar. lastimaba a los animales cuando intentaban comer las pacas de trigo, de primordial importancia para la expansión del oeste americano.

El comercio americano empezó entre 1845 y 1847 . Antes de esas fechas Cuba había absorbido casi exclusivamente la producción total de henequén. En 1845, se embarcaron un poco menos de 65000 arrobas. de las cuales el $85 \%$ era tela para sacos y bolsas para el comercio de La Habana. Siete bodegas de cordeleria en Mérida, cerca de las plantaciones y con mano de obra compartida, preparaban los hilos y hacian cuerda y cable. En 1847, tan sólo 
Estados Unidos importó alrededor de 100000 arrobas de henequén en estado bruto, para procesarse después de la entrega, mientras que los productos manufacturados llegaron a casi 85000 . El consumo total para ese año, tomando en cuenta los productos consumidos localmente como hamacas, cuerda, arneses de henequén y similares alcanzaron un total considerable.

El total. dividido según se indica en el cuadro 2, era mucho mayor que el de 1845 , pero aun así, si se cuantifica en toneladas cortas, es minimo comparado con cifras posteriores. Por ejemplo, en 1880 se exportaron alrededor de 20000 toneladas y, en 1914 , un poco más de 180000 . Resulta significativo el hecho de que en 1847 la exportación de henequén se media en arrobas (de 25 libras cada una).

\section{CUADRO 2}

Consumo y exportación de henequén 1847

\begin{tabular}{|c|c|c|c|c|}
\hline $\begin{array}{l}\text { Clase de } \\
\text { productos }\end{array}$ & $\begin{array}{l}\text { Mercado } \\
\text { principal }\end{array}$ & Arrobas & $\begin{array}{l}\text { Cantidad } \\
\text { Toneladas } \\
\text { cortas }\end{array}$ & Porcentaje \\
\hline
\end{tabular}

\begin{tabular}{clrrr} 
Manufacturados & Local & & & \\
& Cuba & 73759 & 920 & 28.6 \\
Fibras en bruto & Estados & 84648 & 1040 & 32.4 \\
& Unidos & 100000 & 1250 & $\underline{39.0}$ \\
Totales & & 258407 & 3210 & 100.0 \\
\hline
\end{tabular}

FUENTE: Regil y Peón, "Estadística", 313 (adaptada).

La estructura de los precios y sus fluctuaciones evidentemente afectaban el comercio exterior del henequén. Es curioso que una década antes de que grandes volúmenes de fibra yucateca entraran al mercado de Nueva York, ésta había sido capaz de competir en calidad y precio con un producto ruso similar. En aquel tiempo, 1835, la unidad de venta era el tercio (cerca de 50 libras); 150 tercios de henequén yucateco producian 170 pesos, mientras que una cantidad similar de fibra rusa se vendía entre 180 y 185 pesos. El precio de venta aproximada de dos centavos por libra parece haber permanecido estable hasta alrededor de 1848 cuando aparentemente se elevó a tres. Si los costos de producción de la época son confiables, la ganancia producida por el henequén era considerable pero no extraordinaria.

El análisis de los costos de producción estimados de 500 mecates de henequén para los años 1848 a 1868 , revela que la ganancia promedio por mecate era de 60 centavos anuales. A lo largo de este periodo generalmente se consideraba que el rendimiento era de un promedio de cuatro arrobas por mecate (100 libras de fibra). Las cifras de donde se deriva esta ganancia promedio están basadas en varias premisas que podrian afectar el resultado final: que el dueño poseyera ya la tierra sin tener que cargar una hipoteca, que las tasas de interés no aumentarán de $6 \%$, que los adelantos a 
los trabajadores para mantenerlos atados al lugar no representaran una inversión importante, y que el precio de venta (en la hacienda) se sostuviera cuando menos en tres centavos la libra.

Un poco después, en 1876, los escritores señalaron que los gastos se elevaban debido a que los henequeneros se construian a crédito costosas casas e importaban equipo complejo por encima de sus necesidades reales. En ese momento, se pensaba que el costo para producir una arroba de fibra era de cuatro a cuatro y medio reales, dos centavos o un poco más por libra.

Las estimaciones de 1861 presuponian que los principales elementos del costo eran la compra de las plantas, la plantación inicial, dos deshierbes anuales y el desfibrado. Esto último se establecia en la mitad del valor bruto del año. Hasta el final del noveno año, en el que se amortizaban las inversiones de capital original y el agricultor se liberaba de esa carga, el monto de los intereses era un elemento significativo. Las cifras subrayan de un modo práctico el hecho de que incluso en sus primeros dias, el henequén era un negocio que requería una inversión considerable. Cuando menos habia que invertir 2200 pesos antes del cuarto año, cuando se empezaban a obtener las primeras utilidades en efectivo; la práctica posterior difirió este primer corte todavía más tiempo.

Pero también es claro que una vez que la empresa lograba resistir los primeros anos de espera, las utilidades eran apreciables, aun al precio de venta relativamente bajo del henequén, en ese entonces de tres centavos por libra. Precios más altos produjeron obviamente mayor ganancia, pues los costos de operación tendieron a permanecer más o menos estables. El cuadro 3 resume la información del periodo $1848-1868$, y el cuadro 4 proporciona comparaciones para el periodo 1848-1915; el primero se refiere a las utilidades de 500 mecates de henequén, el segundo al precio de venta, costo de producción estimado y tasas de interés.

La evolución de la industria del henequén no repercutió inmediatamente sobre los mayas y los mestizos y sólo levemente sobre los grupos criollos. No había mayor usurpación de la tierra en su expansión. Las haciendas tipo Old Colonial transformaron gradualmente sus propiedades en plantaciones de henequén, 0 se crearon nuevas en las partes escasamente pobladas de la zona Old Colonial. Las que vio Stephens en 1839 tipifican a las primeras. La mayoría de la mano de obra maya de este periodo no era particularmente sediciosa o explotada; el trabajo relacionado con el cultivo y procesamiento del henequén, todavía se encontraba en una etapa manual y los trabajadores no eran apéndices totales de las máquinas. En 1880 , se reconocía que había por lo menos 20767 familias sujetas por deuda. Posiblemente entre los agricultores de azúcar de las Borderlands ${ }^{7}$ y los henequeneros de la zona

La zona de los confines o Borderlands era la región limítrofe de la parte colonizada de la peninsula. Abarcaba tres sectores principales: la comarca de los Chenes: la que se extendía por el camino real, pasando por Tekax, Peto y Tihosuco; y una parte del distrito de Tizimín. Su extremo sudoriental era la lejana población de Bacalar. Más al este y al sur, hacia las fronteras con Belice y Guatemala, se extendia la selva prácticamente desconocida y despoblada, con excepción de algunos grupos mayas, considerados semisalvajes, llamados huites. Esta zona fronteriza era vista. hacia 1820. como la clave del futuro económico de Yucatán. En ella se producian las dos terceras partes de la producción de maiz y más del $90 \%$ del azúcar. 


\section{CUADRO 3}

Utilidades por 500 mecates de henequén $1848-1868$

Pesos por mecate (100 lbs. de rendimiento aproximado)

Año Observaciones $\begin{array}{cc}\text { Balance Anual } & \text { Ganancia } \\ \text { Ganancia Pérdida } & \text { Pérdida }\end{array}$

\begin{tabular}{|c|c|c|c|c|c|}
\hline 1 & Plantación original & & 3.17 & & 3.17 \\
\hline 2 & & & 0.46 & & 3.63 \\
\hline 3 & & & 0.48 & & 4.11 \\
\hline 4 & Primeras hojas comerciales & & 0.31 & & 4.42 \\
\hline 5 & & 0.43 & & & 3.99 \\
\hline 6 & & 0.70 & & & 3.29 \\
\hline 7 & & 1.04 & & & 2.25 \\
\hline 8 & Madurez óptima & 1.10 & & & 1.15 \\
\hline 9 & Amortización completa & 1.17 & & 0.02 & \\
\hline 10 & & 1.35 & & 1.37 & \\
\hline 11 & & 1.35 & & 2.72 & \\
\hline 12 & & 1.35 & & 4.07 & \\
\hline 13 & & 1.35 & & 5.42 & \\
\hline 14 & & 1.35 & & 6.77 & \\
\hline 15 & & 1.35 & & 8.12 & \\
\hline 16 & Rendimiento descendente & 1.10 & & 9.22 & \\
\hline 17 & & 0.85 & & 10.07 & \\
\hline 18 & & 0.80 & & 10.87 & \\
\hline 19 & & 0.65 & & 11.52 & \\
\hline 20 & Abandono & 0.50 & & 12.02 & \\
\hline
\end{tabular}

Ganancia anual media por mecate (sobre 20 años) ... $\quad 0.60$ Media, por 500 mecates (anual) .............. 300.00 Total, por un periodo de 20 años............. 6000.00

FUENTE: Antonio J. Rejón, "Gastos de un plantel de 500 mecates de jenequén", Repertorio Pintoresco (1861), p. 74-79 (adaptado y calculado nuevamente).

Old Colonial, había cierta competencia por los servicios de los. mayas, pero probablemente la clase dominante de cada región estaba unida para mantener las leyes del peonaje (que ninguno había inventado, pero ambos usaron) y en esto tenian el apoyo de los explotadores del palo de Campeche de la West Coast. ${ }^{8}$

Su población era predominantemente maya. Durante la guerra de Castas, que se inició en 1847 y que duró algo más de 50 años, esta región fue también el lugar de los primeros combates, la frontera de los enfrentamientos armados y el límite del avance yucateco frente a los mayas rebeldes.

${ }^{*}$ La zona llamada West Coast abarcaba las poblaciones de Campeche, Hecelchakán, Ceibaplaya e Isla del Carmen. La principal actividad en esta región era el comercio y sus pobladores eran, como en la zona Old Colonial, en su mayoria blancos. 


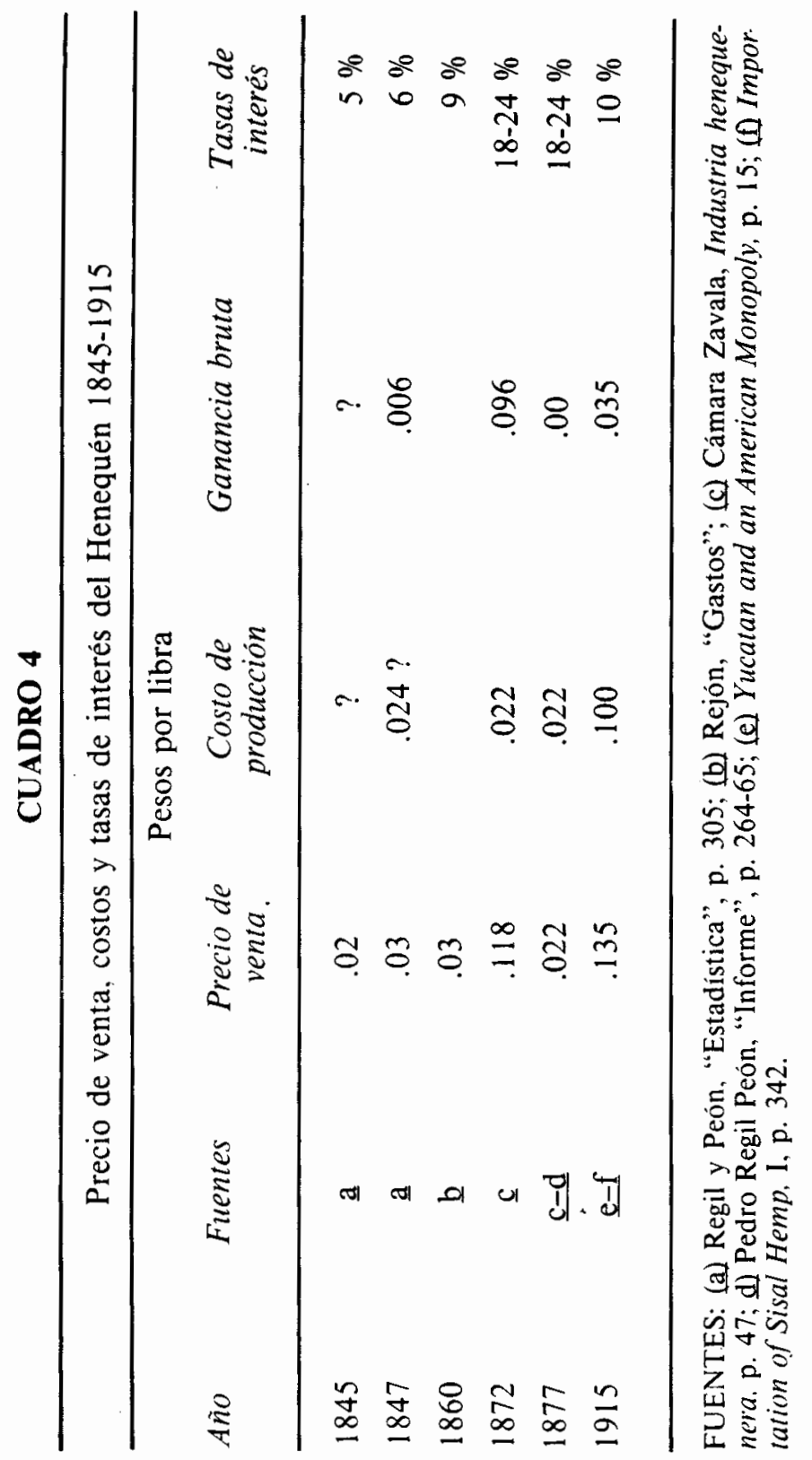


La búsqueda del mejoramiento tecnológico, y el énfasis en las ganancias y en la producción de henequén, coincidian con las otras tendencias "progresistas" de Mérida y Campeche. Las relaciones más estrechas entre Mérida y Cuba, y después con Estados Unidos, siguieron canales comerciales, interrumpidos mucho antes en la historia de Yucatán y tendieron a separar la zona Old Colonial de la zona W'est Coast y las Borderlands, unidas ahora más que nunca a México y a los puertos del golfo por el frágil cordón de las exportaciones de azúcar (además de las de la sal). Como antes se señaló, una indicación palpable de la creciente división fue la búsqueda de un puerto adecuado para exportar el henequén. El camino de Mérida a Progreso, el sitio electo, era un simbolo de la nueva dirección a la que llevaría a Yucatán el comercio del henequén.

La guerra de Castas impulsó el desarrollo de la nueva industria. Desde entonces los yucatecos han considerado al henequén como una planta providencial que salvó a la región de la ruina absoluta cuando el ganado, el azúcar, el algodón, el tabaco y otros productos fueron casi completamente destruidos por las luchas de 1847 a 1853 y el constante resurgimiento de acciones militares cuando menos hasta 1873 .

En muchos sentidos el henequén actuó como tope y amortiguador de impactos. Las plantaciones de henequén que circundaban a la capital hasta una distancia de veinte leguas, actuaban como una muralla, cosa que nunca lograron los pastizales o las milpas. Más importante aûn fue que los refugiados que regresaron del este y del sur - mayas y mestizos por igual- encontraron empleo en una sección recién abierta hacia el oeste y norte de Mérida, en dirección a Motul, asi como en la capital misma. En la ciudad, la manufactura de bolsas se convirtió en un negocio importante. Se estimaba que esta industria pagaba honorarios de tal vez 25000 pesos anuales, y se le conoció como la "Balsa de salvamento en el naufragio general" de la guerra de Castas.

Un investigador meticuloso ha llamado la atención repetidamente sobre las décadas de 1850 y 1860 , que siendo tan estériles politicamente debido a las revueltas y los levantamientos, hicieron factible aglutinar los primeros desarrollos del henequén para formar la industria moderna. Ha señalado que en estos veinte años la planta se cultivó comercialmente a gran escala por mano de obra estable y que se introdujo el crédito comercial, que se inventó la máquina Solis, y que la mecanización adquirió una base firme.

Puede añadirse, paradójicamente, que la naciente industria ayudó a mayas y mestizos, en el sentido de que les ofreció un conjunto de alternativas más favorables (aunque todavía desalentadoras) a las que de otra forma hubieran sido su destino. La creciente necesidad de trabajadores detuvo el tráfico de esclavos mayas que eran embarcados a Cuba, donde generalmente morian. Después de 1859, las presiones económicas locales probablemente tuvieron más efecto que los decretos para detener el desagradable negocio, cuyos operadores, sarcásticos, no dudaban en incluir de vez en cuando en el cargamento a uno o dos soldados mexicanos secuestrados. Además la necesidad de mano de obra abrió una puerta para muchos que preferian trabajar que pelear. Cuando las fuerzas militares estaban en campaña contra los mayas rebeldes se 
dividieron en tropas "sedentarias" y "móviles"; la mayoría de las primeras y no pocas de las segundas se refugiaron en las plantaciones henequeneras, cuyos dueños frecuentemente los protegian del oficial de reclutamiento.

Que los mestizos lograron introducirse de algún modo en la escala social y se convirtieron en luneros (en lugar de mantener su posición tradicional de asalariados) puede deducirse igualmente de esta legislación que detalla los derechos y responsabilidades de los dueños hacia los "/uneros no nativos". La guerra de Castas trazó una nítida y clara línea entre aquellos que estaban dispuestos a aceptar la servidumbre y los que no. Los primeros, mestizos en su mayoría, formaron una reserva de mano de obra de carácter "dulce, suave, respetuoso y obediente". Los segundos eran los "indios bravos" independientes en el sur y los "barbáros" en el este. Entre ellos y las zonas henequeneras había una "tierra de nadie".

Como culminación del complejo henequenero, inmediatamente después de terminar la década de $1860-70$, el puerto de Progreso suplantó oficialmente a Sisal. Para 1873, se habían desplegado caminos carreteros a través de la zona henequenera alta y la capital y su puerto estaban ya casi conectadas por vías férreas; en ese tiempo, los carros eran arrastrados por mulas más que por locomotoras. Para cuando Ober desembarcó en 1880 , el ferrocarril habia sido completamente equipado con carros y máquinas y pasaba a través de "las plantaciones de henequén, con millas y millas de cáñamo de Sisal por ambos lados de la vía... Exceptuando las plantaciones de cáñamo, hay muy poco que lo pueda a uno interesar..." En 1880 el henequén monopolizó la atención y los esfuerzos de la gente de la zona Old Colonial aunque todavia correspondian a una descripción que se hizo de ellos en 1831, en la que se mencionaba que estaban "dispuestos a la cría de ganado y al comercio, en particular el derivado de la carne... y al henequén, en bruto y manufacturado, en lo cual consiste su riqueza".

La situación económica de Yucatán, desde los años inmediatamente posteriores a su independencia política de España y hasta los inicios de la guerra de Castas, no fue particularmente compleja, aunque los problemas que presentó a los yucatecos de la época eran de cierta magnitud. El mayor negocio de la península era la producción de alimentos para sí misma, una actividad que estaba casi por completo en manos de los mayas que trabajaban en las milpas, ubicadas por todas partes en haciendas, cerca de pueblos y ciudades, o en ranchos aislados y rancherías. Cada sección del territorio era casi autosuficiente debido en parte al deficiente sistema de comunicaciones.

La economía estructurada por regiones caracteristica del Yucatán de hoy, donde una región se concentra en la producción de alimentos para dar de comer a los trabajadores de otra zona dedicada a una agricultura comercial de exportación, no habia hecho su aparición, y no lo hizo sino hasta cerca del fin de siglo. La agricultura de milpa absorbió la mayor parte de la mano de obra disponible representada por la masa de nativos, y cualquier otra empresa que los requiriera tenía que adaptarse a la situación o cambiarla. La economía colonial se habia ajustado relativamente a este hecho primordial, pero en su afán por una creciente participación más allá de la península, los yucatecos, que se proclamaron 
después de 1830 "ávidos de progreso y prosperidad", creían firmemente que el cambio era conveniente y que en última instancia beneficiaría a toda el área. incluyendo a los mayas.

Los cambios que se dieron no estaban dirigidos tanto hacia la supresión directa de las formas nativas habituales sino hacia la ampliación de nuevas empresas que se basaban en relaciones un tanto diferentes entre mayas y criollos de las que se acostumbraban anteriormente. La economia colonial se apoyaba en la mano de obra y el esfuerzo de los mayas, pero aceptaba relativamente el hecho de que a los indios les fuera permitido hacer las cosas a su modo. siempre y cuando los productos del tributo se presentaran en los momentos designados. Sin embargo, las doctrinas más nuevas promovieron la tendencia, consciente o inconscientemente, de concebir a los nativos como herramienta humana, como parte de la fuerza de trabajo disciplinada y estable necesaria para la operación de empresas comerciales a gran escala. Como corolario, esa mano de obra también era requerida para proveer los instrumentos necesarios para la expansión de estas empresas -especialmente caminos-. La necesidad de mano de obra creció rápidamente, y con ella la legislación que autorizó el cumplimiento de esas demandas.

Otra tendencia importante se dio en la competencia por la tierra. Tanto el henequén como la caǹa de azúcar necesitaban nuevas áreas: el primero competía menos por el territorio ocupado por los mayas para cultivar maíz que la segunda. La marcada y considerable expansión del cultivo de caña de azúcar hacia áreas indígenas en la zona East Colonial ${ }^{4}$ y sobre todo hacia las Borderlands, tuvo como secuela dificultades tanto de mano de obra como de tierra. Estas tendieron a permanecer latentes, hasta que fueron sacadas a luz y enfocadas hacia disturbios politicos, en parte provocados también por la nueva industria azucarera.

La contracción de los mercados extranjeros para productos tradicionales fue un incentivo para mejorar la tecnología o para buscar una salida más lucrativa para las pequeñas cantidades de capital disponibles en Yucatán. Los hombres concentrados anteriormente en la explotación del palo de Campeche y el ganado, después de 1830 empezaron a invertir en empresas azucareras o henequeneras. Hasta alrededor de 1840 , las primeras tenian un mercado interno casi ilimitado y las segundas uno externo no saturado.

La destrucción de la industria azucarera durante la guerra de Castas. liberó algo de capital y bastante mano de obra para el henequén: su desarrollo anterior fue más lento que el del azúcar. cuyos problemas tecnológicos se resolvieron más fácilmente. La industria del henequén no se modernizo sino hasta después de 1850, aunque los primeros esfuerzos necesarios para su evolución posterior comenzaron desde 1830 . Ante las realidades políticas y sociales de la época, y al desvanecerse la fantasia de las economias basadas en la construcciön de barcos, la producción de café y seda.

"Easl Colonial se refiere a la antigua zona colonial del este. alrededor de las poblaciones de Valladolid. Espita y Tizimín, dedicadas primordialmente a la cria ganadera y con una población mayoritariamente indígena. en una proporción de siete a uno. la mayor del estado. 
surgida entre 1830 y 1847 . las esperanzas para la recuperación económica de Yucatán se fundaron en el azúcar y el henequén.

El surgimiento de nuevas economias ayudó a dividir la península en secciones que tenian sus propias características culturales e incluso étnicas. Paralelamente a esto había diversos objetivos y programas políticos que no sólo reflejaban los choques de intereses entre las secciones. sino la división entre los viejos y los nuevos objetivos al interior de cada sección. Quizá este rompimiento entre la unidad de ideales de la Colonia y de la cultura que se basó en ellos. fue una etapa necesaria antes de la reintegración que se dio como respuesta a las complejidades de los tiempos modernos.

Aunque culturalmente la época moderna empezó a cobrar impulso alrededor de 1835 . económicamente se aplazó hasta alrededor de 1850. cuando los elementos de la industrialización del henequén empezaron a tomar su lugar. En cada caso, la última etapa de la época colonial proporcionó un punto de partida, unas cuantas ideas y un horizonte más amplio, unidos al optimismo característico del siglo xvit: la generación de 1830 a 1860 desarrolló estos magros inicios con sus propias contribuciones y con todo lo que adoptó del resto del mundo occidental. y al hacerlo creó un nuevo contexto no del todo colonial, ni enteramente "moderno". 